\title{
A Bootstrap Approach to an Affordable Exploration Program
}

Richard C. Oeftering

Glenn Research Center, Cleveland, Ohio 


\section{NASA STI Program . . . in Profile}

Since its founding, NASA has been dedicated to the advancement of aeronautics and space science. The NASA Scientific and Technical Information (STI) program plays a key part in helping NASA maintain this important role.

The NASA STI Program operates under the auspices of the Agency Chief Information Officer. It collects, organizes, provides for archiving, and disseminates NASA's STI. The NASA STI program provides access to the NASA Aeronautics and Space Database and its public interface, the NASA Technical Reports Server, thus providing one of the largest collections of aeronautical and space science STI in the world. Results are published in both non-NASA channels and by NASA in the NASA STI Report Series, which includes the following report types:

- TECHNICAL PUBLICATION. Reports of completed research or a major significant phase of research that present the results of NASA programs and include extensive data or theoretical analysis. Includes compilations of significant scientific and technical data and information deemed to be of continuing reference value. NASA counterpart of peer-reviewed formal professional papers but has less stringent limitations on manuscript length and extent of graphic presentations.

- TECHNICAL MEMORANDUM. Scientific and technical findings that are preliminary or of specialized interest, e.g., quick release reports, working papers, and bibliographies that contain minimal annotation. Does not contain extensive analysis.

- CONTRACTOR REPORT. Scientific and technical findings by NASA-sponsored contractors and grantees.
- CONFERENCE PUBLICATION. Collected papers from scientific and technical conferences, symposia, seminars, or other meetings sponsored or cosponsored by NASA.

- SPECIAL PUBLICATION. Scientific, technical, or historical information from NASA programs, projects, and missions, often concerned with subjects having substantial public interest.

- TECHNICAL TRANSLATION. Englishlanguage translations of foreign scientific and technical material pertinent to NASA's mission.

Specialized services also include creating custom thesauri, building customized databases, organizing and publishing research results.

For more information about the NASA STI program, see the following:

- Access the NASA STI program home page at http://www.sti.nasa.gov

- E-mail your question via the Internet to help@ sti.nasa.gov

- Fax your question to the NASA STI Help Desk at 443-757-5803

- Telephone the NASA STI Help Desk at 443-757-5802

- Write to: NASA Center for AeroSpace Information (CASI) 7115 Standard Drive Hanover, MD 21076-1320 


\title{
A Bootstrap Approach to an Affordable Exploration Program
}

\author{
Richard C. Oeftering
}

Glenn Research Center, Cleveland, Ohio

Prepared for the

Space 2010 Conference and Exposition

sponsored by the American Institute of Aeronautics and Astronautics

Anaheim, California, August 30 to September 2, 2010

National Aeronautics and

Space Administration

Glenn Research Center

Cleveland, Ohio 44135 
This report contains preliminary findings, subject to revision as analysis proceeds.

Trade names and trademarks are used in this report for identification only. Their usage does not constitute an official endorsement, either expressed or implied, by the National Aeronautics and Space Administration.

Level of Review: This material has been technically reviewed by technical management.

Available from

NASA Center for Aerospace Information 7115 Standard Drive

Hanover, MD 21076-1320
National Technical Information Service 5301 Shawnee Road Alexandria, VA 22312

Available electronically at http://www.sti.nasa.gov 


\title{
A Bootstrap Approach to an Affordable Exploration Program
}

\author{
Richard C. Oeftering \\ National Aeronautics and Space Administration \\ Glenn Research Center \\ Cleveland, Ohio 44135
}

\begin{abstract}
This paper examines the potential to build an affordable sustainable exploration program by adopting an approach that requires investing in technologies that can be used to build a space infrastructure from very modest initial capabilities. Human exploration has had a history of flight programs that have high development and operational costs. Since Apollo, human exploration has had very constrained budgets and they are expected be constrained in the future. Due to their high operations costs it becomes necessary to consider retiring established space facilities in order to move on to the next exploration challenge. This practice may save cost in the near term but it does so by sacrificing part of the program's future architecture. Human exploration also has a history of sacrificing fully functional flight hardware to achieve mission objectives. An affordable exploration program cannot be built when it involves billions of dollars of discarded space flight hardware, instead, the program must emphasize preserving its high value space assets and building a suitable permanent infrastructure. Further this infrastructure must reduce operational and logistics cost. The paper examines the importance of achieving a high level of logistics independence by minimizing resource consumption, minimizing the dependency on external logistics, and maximizing the utility of resources available. The approach involves the development and deployment of a core suite of technologies that have minimum initial needs yet are able expand upon initial capability in an incremental "bootstrap" fashion. The "bootstrap approach" incrementally creates an infrastructure that grows and becomes self sustaining and eventually begins producing the energy, products and consumable propellants that support human exploration. The bootstrap technologies involve new methods of delivering and manipulating energy and materials. These technologies will exploit the space environment, minimize dependencies, and minimize the need for imported resources. They will provide the widest range of utility in a resource scarce environment and pave the way to an affordable exploration program.
\end{abstract}

\section{Introduction}

This paper examines the potential to build an affordable sustainable exploration program by adopting an approach of investing in technologies that can build a space infrastructure from very modest initial capabilities. The main focus is not getting humans to the moon at a certain date. Instead the focus is on getting lunar resources and establishing a resource infrastructure to yield an affordable program.

Since Apollo, human exploration has had very constrained budgets and they are expected be constrained in the future. Faced with high operations costs combined with level budgets it becomes necessary to consider retiring established space facilities in order to move on to the next exploration challenge. The Constellation program sought to retire key assets that are viewed as a financial burden and a barrier to expanding exploration.

- Retiring the Space Shuttle after 2010

- Retiring the Space Station after 2015

Human crews are resource intensive and thus missions beyond Earth orbit have limited duration that limits what can be accomplished. Further the usable payload capacity is dominated by crew needs leaving very little room for science and infrastructure payloads.

What is most alarming about human exploration is the destruction or abandonment of perfectly good hardware. Each crewed lunar mission results in the abandonment of the Altair lunar lander Decent Module, the total destruction of the Ascent Module, and the destruction the of majority of the Orion Vehicle.

One way to illustrate this point is to show, side by side, how a human crew compares with a robotic mission of the same scale. Using a conservative mass fraction calculation for a vehicle traveling from Low Earth Orbit (LLO) the estimate space transportation cost per kilogram is: ${ }^{1}$ 
- $\$ 20,000 / \mathrm{kg}$ to Low Earth Orbit (LEO)

- $\$ 60,000 / \mathrm{kg}$ to Low Lunar Orbit (LLO)

- $\$ 100,000 / \mathrm{kg}$ to Lunar Surface Landing (LSL)

A crew mission requires two separate launches- Orion on an Aries I and Altair on an Aries V. A Cargo Lander (Altair cargo variant) requires a single Aries V launch.

Delivered Mass:

- Orion Mass LLO $=20,200 \mathrm{~kg}$

- Altair Mass LSL $=20,100 \mathrm{~kg}$

- Cargo Mass LSL $=26,100 \mathrm{~kg}$

Table 1: Comparison of Crewed Missions Versus Cargo Missions

\begin{tabular}{|l|l|l|l|}
\hline \multicolumn{2}{|c|}{ Crewed Mission } & \multicolumn{2}{c|}{ Cargo Mission } \\
\hline Elements & Transport Cost & Elements & Transport Cost \\
\hline Orion + Altair Lander & $\$ 3.22 \mathrm{~B}$ & Cargo Lander & $\$ 2.6 \mathrm{~B}$ \\
\hline Payload Value & $\$ 0.15 \mathrm{~B}(5 \%)$ & Payload Value & $\$ 1.45 \mathrm{~B}(56 \%)$ \\
\hline
\end{tabular}

This table reflects the fact that the Altair Ascent Module is destroyed; the Decent Module is abandoned on the surface and the Orion Service Module destroyed and only portions of the Orion Crew Module usable after a single mission. Only about $1500 \mathrm{~kg}$ is delivered to the lunar surface. Meanwhile, the Cargo Lander delivers 14,500 $\mathrm{kg}$ to the surface. There is nearly a 10:1 payload benefit in favor of robotic over human crews. Since the Cargo Lander Systems are intact it is possible to scavenge the hardware for spares or as a source for building infrastructure. By scavenging this hardware the surviving value of the delivered mass may approach $100 \%$.

Of the reasons cited for Apollo cancellation, "high recurring costs" should be of concern for the current program. ${ }^{2}$ Public interest may be high enough to sustain a lunar program initially. But public support may wane once it sees repeated destruction of "perfectly good" spacecraft at taxpayer expense. An affordable program must emphasize preserving its high value space assets, but moreover, build a suitable infrastructure that reduces cost. An infrastructure that preserves space hardware by refueling, refurbishing, and maintaining space assets will make space exploration more affordable. ${ }^{3}$

Concepts for in-space refueling of reusable spacecraft by a prepositioned propellant infrastructure have been studied in the past. Some concepts assume the refueling propellants would be launched from Earth at very high cost. Other concepts exploit lunar resources as a source of oxygen but not fuel. Most of these concepts also assume that very costly humans missions would deploy the lunar propellant infrastructure which diminishes the benefits of the a lunar propellant. ${ }^{4}$ What is needed is a propellant infrastructure that precedes human missions.

The Bootstrap Approach, described in this paper, attempts to create the infrastructure from scratch using the least amount of hardware from Earth. The "bootstrap" approach, is an investment strategy that starts with existing capability and expands a capability by exploiting local resources to create a self sustaining architecture. It is a slow but constant progression where a "mentality of scarcity" pervades so that no resource goes unused. This extremely frugal but opportunistic approach is viewed as the best way to assure that deployment and logistics costs are kept to a minimum.

The Bootstrap Approach involves an innate capacity to grow and build an ever wider infrastructure. As this micro-scale lunar economy grows it becomes capable of exporting surplus products to the larger space infrastructure. Exports would include highly valued volatiles, propellants and other materials like metals for construction of infrastructure. Conceivably, in situ materials can be combined with imported technologies from Earth to build facilities and even spacecraft hardware. The Bootstrap Approach is an investment strategy that defers near term payoff for a much greater long term payoff. This includes deferring human crews in favor of tele-operated robotics in the near term.

This approach has a historical analogy. In early American colonial period successful settlements started quite small but they established resource independence early on. Their economies slowly grew, and produced products for trade and even export. Eventually, they became capable of producing more sophisticated products including ships and railroads which would eventually lead to America becoming a world trading power. Like colonial America, the growth process is a very slow and methodical. It will take years to evolve but in the end a very permanent infrastructure will emerge that will change how humans explore and develop space. 


\section{Infrastructure for a Supportable, Sustainable Program}

\section{A. Human and Robotic Logistics}

Humans are fragile, perishable and their resource needs are time critical thus failures or interruptions of the flow of resources cannot be tolerated. Logistics based on transportation from Earth has also proven to be relatively fragile. System reliability and availability is time dependent and long missions increase the risk of crews being stranded. Further, beyond Earth orbit the options for a quick rescue are quite limited. Local volatile resources like oxygen and water, if available, would provide an added level of safety and mitigate risk.

As illustrated in the earlier comparison of the two versions of the Altair, there is a 10:1 payload ratio in favor of the uncrewed cargo lander. The dramatic difference in capacity indicates the much higher productivity of robotic missions. Unlike human missions that discard most of the vehicle, the uncrewed cargo lander delivers $14.5 \mathrm{mt}$ of payload. But in addition, since the lander is fully intact there is another $12.5 \mathrm{mt}$ of fully functional flight hardware and residuals available. By salvaging this hardware the ratio becomes 18:1 in favor of robotics.

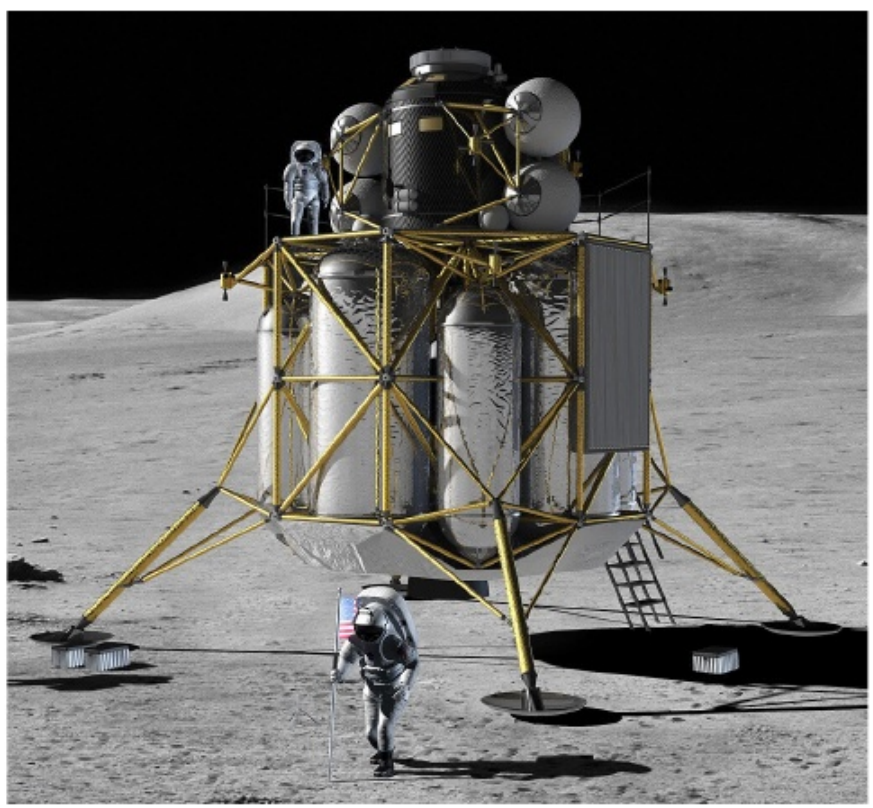

Figure 1: Altair Lunar Lander. In a Bootstrap Approach a lunar resources infrastructure would be established to refuel a reusable spacecraft.

Clearly an infrastructure that allowed spacecraft to be fully reused is needed to minimize human exploration costs. One approach is to extract propellants from the lunar surface and build a refueling infrastructure that enables reusable landers. Such an infrastructure allows much more payload to be dedicated to human support logistics and delivery of permanent facilities.

The need to return crews Earth is a barrier to building this infrastructure. In other words, building an infrastructure to make human exploration affordable cannot be built by human crews. Tele-robotics is essential to minimizing the logistics footprint while providing high levels of productivity. Robotic dependencies are quite simple, primarily, electric power. Rather than wait for the development of new launch vehicle Robots can be delivered using existing launch vehicles. The technology development for the infrastructure can begin now and a lunar resource infrastructure can be deployed about a decade. The robotic build up of this infrastructure simply becomes an extension of the robotic precursor missions prior to human operations.

\section{B. Updated Approach to Lunar Resources}

The current In-situ Resource Utilization (ISRU) strategy was formed well before there was solid evidence of water on the moon. The current program favors extracting volatiles from the lunar regolith which is a conservative approach that would be applicable to any location on the lunar surface. The emphasis has been on crew water and oxygen and not as a major propellant producer for lunar operations. ISRU is not on the program critical path and no plans show significant reliance on in-situ resources for lunar applications. However, there is a growing body of evidence that lunar water, hydroxyl and other volatiles are present at the lunar poles. 
Several separate missions have provided evidence of water on the moon including the Clementine, Lunar Prospector, India's Chandrayaan-1, Japan's SELENE (Kaguya) and most recently Lunar Recognizance Orbiter (LRO) and its secondary payload the Lunar Crater Observation and Sensing Satellite (LCROSS). Further, there is strong evidence that the moon actually produces water through the interaction of the solar wind composed of hydrogen ions and the native oxygen on the lunar surface. This mechanism implies that water is a renewable resource and not dependent on rare encounters with comets or ancient geologic events. These missions have produced extremely encouraging evidence that a critical resource exists in enough abundance that it can reshape the future of human exploration. ${ }^{3}$

A major shift in focus is required to swing efforts toward exploiting volatile resources in a manner that builds an infrastructure. The prior uncertainties regarding lunar water have inhibited serious studies and the development of strategies and technologies to exploit these resources. Lunar ISRU has been characterized as enhancing and not enabling. This assessment is fundamentally wrong. A lunar resource based infrastructure enables long term space operations, it enables low cost space propulsion, and it even enables space commerce.

This is not the first paper to suggest that In Situ Resource Utilization should precede human return to the moon. ${ }^{4}$ The LUNOX concept eliminated the need for a separate command module and lunar module and reduced the overall size of the launch vehicle. The launch vehicle development and recurring launch cost would be less than a conventional approach. The cost reduction was expected to save $\$ 6$ billion by the first human flight. However, a new launch vehicle was still required. A substantial lunar infrastructure including robotic regolith mining, processing equipment and a nuclear reactor needed to be delivered. The case for LUNOX was based on reducing the size of a crewed launch vehicle and lunar lander yet it proposed a 60 metric ton infrastructure. The LUNOX system plus new launch vehicle development put the combined cost around \$20 (FY93) billion.

The lesson learned is that exploiting ISRU should be consistent with minimizing vehicle cost and not require a large vehicle or human crews for systems deployment. The bootstrap approach minimizes costs upfront by employing only an existing launch capacity. The LUNOX approach also came too early to benefit from the new evidence that large quantities of water exists at the lunar poles. In an updated approach lunar water provides a complete fuel/oxidizer propellant solution.

\section{Resources to Meet Robotic Needs}

Although the ultimate goal is to establish a volatile resource infrastructure the initial focus must be on resources needed for robotics. Though robots are logistically simple they still will need frequent maintenance to remain productive. Robots will suffer wear and tear in the rugged lunar environment and the resulting maintenance threatens their cost effectiveness if it results in a steady stream of replacement parts. Since the goal is to minimize logistics and supportability costs, the robotic program must take great pains to prevent creating the very logistic problem it intended to avoid.

The logistics independence strategy seeks to achieve a high level of material independence as early as possible in the robotic phase. Unlike earlier concepts this approach seeks to meet every possible need by exploiting the local environment. It is not limited to volatiles like oxygen and water but involves solar energy and non-volatile mineral assets. The metal and ceramic content of the lunar surface can provide the resources for building infrastructure and maintaining it. Achieving logistics independence requires NASA to develop new technology solutions. Some technologies will be embedded in the flight hardware design, while others, will be new processes specifically designed to operate in the space environment.

The hardware must be designed to simplify in-situ repair or restoration of worn and damaged hardware. Further, these in situ repair technologies must be able to exploit the local space environment, as well as, the materials. A process that requires special containment or special imported process materials must be avoided.

Logistics independence alone will not create the needed infrastructure. Logistics independence simply enables the robotic precursors to minimize the logistics of sustaining itself and focus energy on building infrastructure. The focus on resources and methodically building an infrastructure bridges the gap between robotic and human missions. This "bootstrap approach" makes human exploration affordable by deferring human missions, in the near term, to keep the initial cost low and builds a resource infrastructure that assures that future operation cost is minimized. The resulting capabilities and technology base will continue to payoff for human exploration over the long term. 


\section{Bootstrap Approach}

To Bootstrap: "to promote or develop by initiative and effort with little or no assistance,... to use resources to acquire more resources."

\section{A. Bootstrap Ground Rules}

The Bootstrap Approach involves the overall infrastructure architecture encompassing multiple systems. The ground rules, below, help define a general "Concept of Operation" for the overall bootstrap architecture.

- Use available Launch Vehicles: Exploit existing launch capabilities; if a more capable launch system evolves then exploit it. The bootstrap approach avoids depending on the development of a new launch vehicle where costs tend to diminish the benefits.

- Start Small, Simple, and Survivable: Start with a small amount of initial resources. Simplify operations and dependencies by engaging only in activities immediately relevant in establishing survivable capability. Eliminate anything that does not support the bootstrap process. Eliminate any high consumption or time dependent elements.

- Preserve and Reuse Assets: Conserve all resources, scavenge unused resources. Every piece of hardware must be designed to provide the greatest possible utility and support reuse. Establishing permanent and expanding capability in a resource scarce environment involves little tolerance for discarded hardware.

- Use Resource Independence Strategy: The bootstrap approach is a resource strategy. Minimizing imported logistic resources and effectively maximizing in situ resources are essential.

- Minimize Imported Resource: Avoid dependency on any resource or consumable that cannot be found in the lunar environment.

- Maximize In situ Resources: Processes that exploit local resources have a higher chance of survival and will have fewer dependencies.

The infrastructure will always need some imported materials but minimizing the dependency at the subsystem level assures system level independence.

- Bootstrap Power Resource First: The base resource (electric power) is common to all systems. As this resource expands, then the dependent technologies also expand in capability.

- Employ Non-Volatile Resources: Using the base resources, extract and employ non volatiles in creating or expanding the infrastructure. This involves taking non-volatile materials from scavenged sources or in situ sources and creating simple components by fabrication methods suited for the lunar environment.

- Establish Volatile Infrastructure: Using base resources, non volatiles, and fabrication technology build an infrastructure to access volatile lowlands, extract volatiles, and convert them into products that supports bootstrap operations but also serves as the primary export products.

- Export in Situ Resource Products: Acquisition of volatiles must have a channel for exporting them to potential lunar users and users in Cis-lunar space.

\section{B. Bootstrap Technology Criteria}

Bootstrap involves leveraging initial resources and capabilities to acquire more resources and in turn expand capabilities. Bootstrapping is a repeating cycle that ultimately expands the initial capability into one that can produce a high value export product that pays back the initial investment. A common plant seed can be regarded as a metaphor for bootstrap capability. The entire premise of the bootstrap is to avoid the huge cost of shipping the entire infrastructure. Bootstrap technologies can be defined as the technologies that perform the growth cycle with very limited initial resources. For lunar applications this implies some form of manufacturing technology that can convert scavenged assets and lunar materials into a capabilities. Such a capabilities would include tools, fixtures, and other aids that are not otherwise part of the initial inventory. Bootstrap technologies would be selected based on the following criteria:

- Process Environment Compatibility: Environment compatibility minimizes process support and containment equipment and, in turn, simplifies operations and logistics. Consistent with the bootstrap approach ground rules, process technologies that are compatible also reduce resource dependency. Process technologies that actually exploit the environment will be most suitable.

- Dependencies (measure of complexity): The process dependency criterion can be regarded as a measure not only of logistics, but as a measure of a system's operational complexity. A critical consumable dependency is one that effectively shuts down the process if it is exhausted. A process technology must be evaluated for 
hidden dependencies such as consumables that are perishable or have a limited shelf life. Process technologies must also minimize dependency on special pre-processing and post processing steps.

- Resource Effectiveness: Resource effectiveness extends the resource independence strategy to technology selection. Technologies that minimize imported resource dependencies and a maximize the exploitation of in situ resources are consistent with the bootstrap approach. This is necessary to assure that the infrastructure that is intended to minimize launch mass does not itself create added demand for launched mass.

- Process Utility: Process utility is intended to assure that greatest possible utility is provided by a small set of capabilities. A process with high utility would handle a wide array of materials and apply to a wide array of applications.

An example of Bootstrap technology is a process that produces tools that in turn produces other products. A classic example is the "blacksmith" that effectively meets the above criteria. A blacksmith operation was compatible with primitive environments, it had simple dependencies, it effectively used available resources, and provided broad utility. Early colonies relied on blacksmiths to service and fabricate tools for virtually any metal application from cookware, to construction implements, to weapons. Blacksmiths were also uniquely capable of producing their own tools. An analogy of this capability for the lunar applications would be a technology that could construct tools, or building fixtures that in turn serve in fabrication and repair from materials scavenged from flight hardware.

\section{Establishing Initial Bootstrap Capabilities}

\section{A. Payload Delivery and Logistics}

To avoid engaging in a costly launch vehicle development program the bootstrap systems are assumed to be delivered by an unmanned lander launched by an available Evolved Expendable Launch Vehicles (EELV) such as the Atlas or Delta heavy lift vehicles. An Aries V scale vehicle could be employed when available but this approach will not explicitly require one up front.

The payload capacity of these EELVs to Low Earth Orbit (LEO) spans a range from 10,000 to 20,000+ kg. ${ }^{6}$ This LEO capacity can conservatively land a mass of roughly $20 \%$ that mass on the surface of the moon. Therefore, it is safe to assume a landed vehicle mass in the range of 2000 to $4000 \mathrm{~kg}$ for lunar applications. Using the Altair Cargo Lander as a reference, a lunar lander payload is no more than $55 \%$ the total landing mass. ${ }^{7}$ That puts the practical payload mass in the range of 1100 to $2200 \mathrm{~kg}$.

Logistic resupply flights would be limited to no more than one per year and that capacity is assumed to be shared with delivery of additional bootstrap elements. Under these constraints, the initial robotic system will need to be highly independent of logistics.

\section{B. Highland and Lowland Sites}

The southern pole of the moon has unusual terrain features including lowlands with permanently dark craters with substantial amounts of frozen water and highlands with near constant sunlight exposure. The highlands represent an opportunity to exploit solar energy while lowlands represent a vast source of water as a consumable or as a propellant and thus a suitable bootstrap location. The presence of water has been confirmed by the recent Lunar Reconnaissance Orbiter (LRO) and the Lunar Crater Observation and Sensing Satellite (LCROSS) mission in 2009.

In this paper, it is assumed that at least one precursor mission has landed on the moon and made direct "ground truth" confirmation of the nature of the volatile resources and confirmed that enough material is within reach of extraction techniques without the need for major excavation facilities. Volatile resources are concentrated in very cold and perpetually dark craters and robotic units will require substantial external power infrastructure to stay operating.

Mt Malapert provides nearly $90 \%$ constant sunlight, a nearly ideal setting for a solar energy based power system. ${ }^{5}$ Unfortunately, Malapert is $5 \mathrm{~km}$ high and some $100 \mathrm{~km}$ away from the most likely source of volatiles. The distance and elevation between these sites makes it difficult to exploit both resources at the same time. In the bootstrap approach the development of the base resource at Malapert will take precedence. Connecting the vast power potential of Malapert with the vast water resources of the southern craters is one of the main challenges of the bootstrap approach.

Malapert is the best site to iniate bootstrap capability due to the access to the solar energy resource. Much of the initial effort will focus on erecting and expanding a solar power infrastructure. Initial power would be focused on extracting non volatiles and fabricating additional power generation and transmission capacity. Additional launches 
may be needed to provide key components. The abundant solar power at Malapert will be used to help extract nonvolatile resources like metals and non metals to construct a power transmission infrastructure. Simple support structures can be scavenged from landers and mixed with in-situ materials in fabrication processes (described later). Linking solar highlands with the volatile lowlands via conductive power lines will require miles of conductive wire. The alternative microwave transmitted power may need multiple microwave receiver/transmitter towers. In either case power lines or microwave antennas will likely need a series of supporting towers.

\section{Bootstrap Power}

The greater the power capacity the more capable the system is and the faster that bootstrap progresses. Erecting the power infrastructure requires an initial capability. For this study we assume that the initial capability is limited to roughly $10 \mathrm{~kW}$. The solar panels used on Orion produce from 5.5 to $7 \mathrm{~kW}$ of power depending on temperature. The Mobile Power Unit (MPU) intended for the lunar surface systems uses two Orion arrays with total $10 \mathrm{~kW}$ capacity and $10 \mathrm{kWhr}$ of batteries and related avionics controls. The unit also supports wireless LAN and S-Band communications including two S-Band high gain antennas for Direct with Earth (DWE) links. The overall weight is around $1200 \mathrm{~kg}$ and suitable as an EELV cargo. The MPU can traverse dark areas on battery.

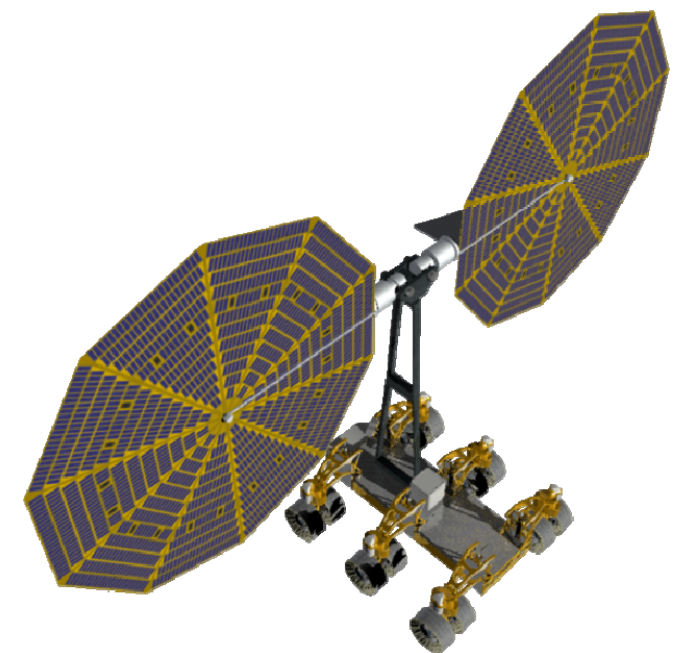

Figure 2: Mobile Power Unit. Solar arrays deployed shown mounted on a robotic mobility unit. (Credit: NASA Lunar Surface Systems)

An alternative nuclear option may be the Mobile Fission Power System (MFPS) which also offers $10 \mathrm{~kW}$ of power, day or night, and is deemed adequate for initial bootstrap operations. The MFPS frees the program of the strict dependency on solar power, simplifies power deliviery and expands robot mobility particularly in solar poor areas $^{8}$. It is envisioned that this unit would be used first in setting up the main power site in the Solar Highlands. Once the fixed site is operational the MFPS unit is transported from site to site primarily along the power transmission route between the Solar Highlands and Volatile Lowlands. It would support the robots setting up towers, running conductors or establishing microwave power links.

The table 2 below, provided by Mason at Glenn Research Center, indicates the mass of the MFPS exceeds the limits of the EELV launched lander vehicles thus the system requires two missions for delivery. A robotic system for deployment would need a third vehicle. Even a modest reactor may cost over $\$ 1$ billion to develop and deliver. Using two EELV heavy launch vehicles is assumed to total $\$ 600$ million. In contrast, the MPU's solar power arrays can be, literally, bought off-the-shelf. The MPU would likely cost $25 \%$ of the cost MFPS and be delivered in one mission.

Table 2: Mobile Fission Power System (Ref Mason)

\begin{tabular}{|l|c|}
\hline \multicolumn{1}{|c|}{ MFPS Subsystem } & Mass (kg) \\
\hline Power Plant & 1615 \\
\hline Power Management \& Distribution & 415 \\
\hline Shielding Water & 1310 \\
\hline Total Estimate & 3340 \\
\hline
\end{tabular}


Nuclear cannot be expanded in situ and thus any expansion of power must focus on solar power. Delivery of a large fission systems will require a large launch vehicle that is assumed to be beyond the bootstrap phase. This option is worth considering if it is deemed more practical than running long power lines between the highlands and lowlands. For purposes of this paper, it is assumed that a MFPS is an option for initial capability but the primary power infrastructure used for propellant production will be solar. At this point, the feasibility and cost-benefit analysis of nuclear versus solar in the initial bootstrap is left for a future study.

\section{Bootstrap Communications}

The establishment of communications to Earth is essential for the bootstrap approach. Without a lunar orbiting satellite system a surface based Direct-With-Earth (DWE) system is assumed. Once again, the prime location is Mt Malapert. Linking Solar Highlands with Volatile Lowlands by communication links may need a series of intermediate sites. Deployment of communications will occur concurrently with the power transmission infrastructure. Even if the communication is transmitted entirely by wireless means the links will still need to tap into the power system. Volatile Lowlands cannot be seen directly by Earth viewing communications and thus requires relay sites that see down into the craters.

Unlike Mars the Moon has a relatively short signal turnaround delay (about $4 \mathrm{sec}$ ) for Earth-Lunar communications. Unlike the Space Station, travelling in a $90 \mathrm{~min}$ orbit, lunar communication is not subject to frequent Loss of Signal (LOS) interruptions. Therefore the robots do not need extensive autonomy. In the bootstrap approach robots are viewed as extensions of their human operators. Autonomy is needed if a robot's communication link is lost. In fact, the first autonomous act may be to reestablish communications. Except for downtime for battery charging (or battery swap) these units can work around the clock and could be supported by multiple shifts of human operators.

\section{E. Bootstrap Tele-Robotics}

Science rovers avoid obstacles and hazards that pose a threat to the science mission. Unlike science rovers, bootstrap robots must be very rugged to tolerate "getting dirty". Bootstrap operations will need multiple robotic units working in cooperation. This provides redundancy, but further, robots may be used to assist one another. If a robot is inadvertently overturned or stuck in terrain, the other unit can rescue it. Robots will be used in maintaining surface systems and also maintaining each other.

Virtually every conceivable operation will be performed by these tele-operated robots. Moving equipment, clearing rocks and hazards and moving regolith will require robust units while maintenance needs a highly dexterous class of robots. A diverse mix of mobile and stationary robots of various sizes will be needed. Robotic units will be designed to operate in a hard vacuum and tolerate very low temperatures. A portion of the robotic population will be stationary industrial style robots working in fixed locations. Stationary robots would perform specialized tasks like welding or fabrication. Stationary robots can be moved from site to site by mobile robots.

For detailed operations that would normally require a human hand, dexterous robots like the anthropomorphic Robonaut would be suitable. Ultimate mobility requires legs capable of crossing varied terrain and, when needed, climbing over obstacles. Except for propulsive hoppers, walking robots will provide the greatest mobility. The ATHLETE robot can be described as walking-rolling hybrid with a remarkable degree of articulation. The prototype unit in the figure below is a suitable scale ${ }^{9}$. The symmetry and open frame structural approach makes it a good candidate to be fitted with thrusters to serve as a short range propulsive hopper. With the added ability to fly it will be able to make short range sorties to drop equipment into areas or across terrain that would otherwise be too hazardous to traverse. 


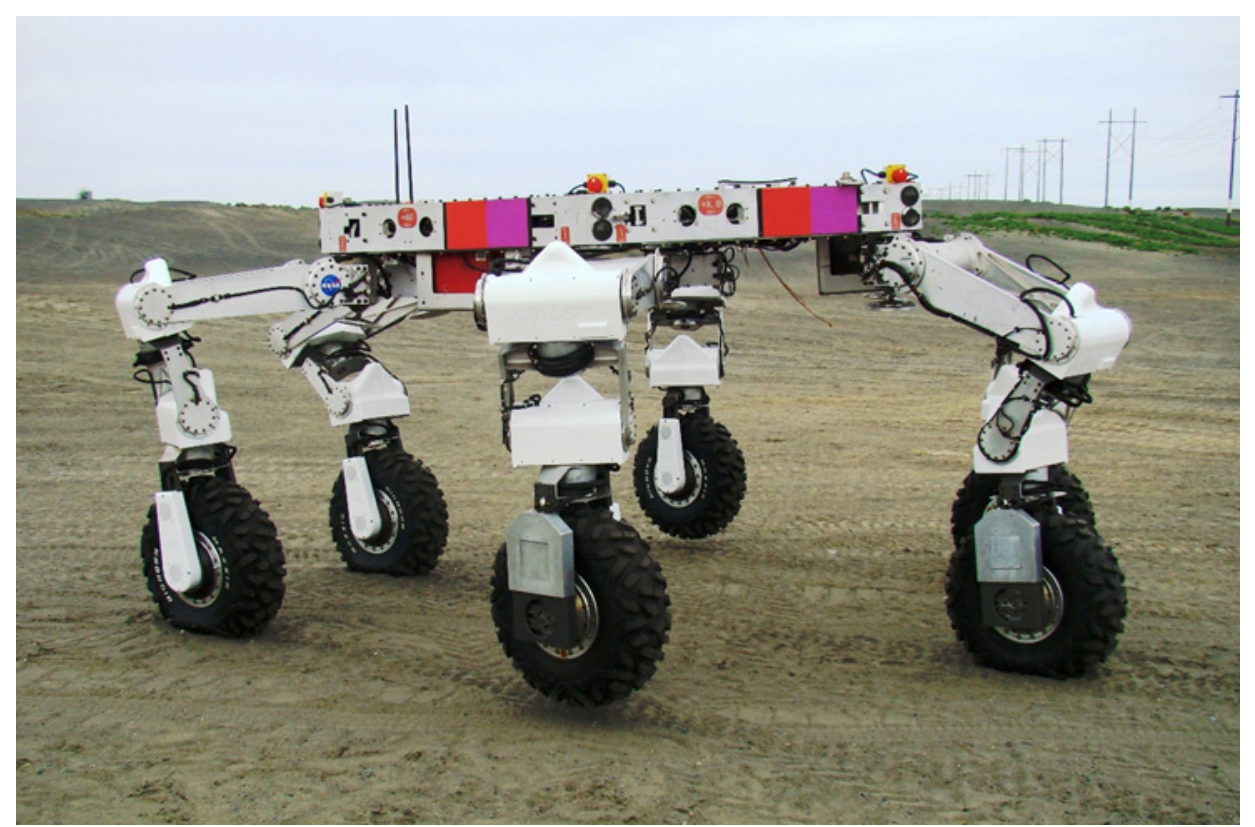

Figure 3: ATHLETE prototype at Moses Lake field tests. (Photo R. Oeftering)

\section{Bootstrap Technologies}

\section{A. Preserving Flight Hardware Assets by Scavenging}

To achieve "Resource Independence" from costly Earth based logistics it is necessary to design all parts of the system to provide the greatest possible level of utility with the minimum need for supporting resources. One approach is to scavenge (or salvage) hardware and materials from the lander spacecraft. The scavenging hardware may serve as maintenance spares at various levels of assembly which in turn preserves the operation of lunar assets. Alternatively the scavenged hardware and materials may be reused and combined with materials from in situ sources to build parts of the expanding bootstrap infrastructure.

In the Bootstrap Approach the robotic lander vehicle is regarded as part of its own payload. That is, the flight systems are designed to be reused in the surface infrastructure. This has the effect of reducing the need to carry spares as payload. Elements of the navigation, communications, power system, in particular can serve as a source of spares if the vehicle and lunar surface system payload share a common architecture. Further the avionics, structures and mechanisms can be reused to support site operations. In order to do this successfully, equipment designs must have interchangeable or reconfigurable features. Further, the design must be easy to disassemble and reintegrate into another applications.

Much of this work is already done by the Air Forces Plug-N-Play Satellite program ${ }^{10}$. The intent was to develop a satellite that could be assembled in a variety of configurations and launched within 6 days. The easy access, self organizing networks, and broad reconfigure-ability, actually serve to make the system readily reusable. For flight hardware that cannot be reused or reconfigured the next option is to scavenge components for in situ repairs or new applications. Complex assemblies are most often repaired by a component replacement.

System designers can simplify repairs by embedding component level diagnostics, prognostics and self test capability. Physical access can be simplified by applying "Plug and Play" principles that permit repairs without violation of system integrity. Designs that are repairable are also more scavengable, re-useable and this ultimately extends useful life of the hardware.

Hardware that is no longer useful in its original state can be salvaged for its material content. The materials may be reused for completely new applications or as part of a repair. Material that cannot be found in the lunar environment is particularly useful. Metals provide the most versatility across a wide range of applications. Scavenged metal can be used in repairs and fabrication of new hardware including elements of the ISRU infrastructure. 


\section{B. Non-Volatile In-Situ Resources}

Fabrication is needed to convert materials into useful products. In the initial phase scavenging the lander for metal feedstock is a near term alternative to ISRU metals. However, a robotic lander may only provide a few hundred kilograms at best. Considering the need for metal conductors the bootstrap approach will stall if ISRU metal feedstock is not provided. Therefore, the extraction of non-volatile lunar materials specifically metals is enabling for bootstrap approach. Due to the technical challenges the program must make an investment early in metallic and non metallic material extraction and separation technologies.

\section{Non Volatile Resource Processing}

As noted earlier most resource utilization studies focus on mining resources with variations of conventional mining equipment. The best solution however is to use all-electric electrostatic or electromagnetic methods of processing the abundant fine lunar regolith. It eliminates massive excavation, rock processing equipment. Conveying powdery materials by electric techniques may require more energy per kilogram. However, in a lunar architecture it is much more important to keep peak power demand low. Processing regolith and other solids as a small continuous stream of materials is far more effective use of the power resource. ${ }^{11}$

Table 3: Lunar Surface Materials

\begin{tabular}{|l|c|}
\hline \multicolumn{1}{|c|}{ Material } & Percentage \\
\hline Oxygen & $40-45 \%$ \\
\hline Silicon & $21 \%$ \\
\hline Iron & $6-15 \%$ \\
\hline Aluminum & $5-13 \%$ \\
\hline Calcium & $8-10 \%$ \\
\hline Magnesium & $6 \%$ \\
\hline Titanium & $1 \%$ \\
\hline Sodium & $1 \%$ \\
\hline
\end{tabular}

The moon is composed primarily of metal oxides. Once oxygen is removed there a substantial portion of the mass in metallic. Iron, aluminum, titanium and magnesium are all useful construction materials. Most techniques developed so far have focused on extracting volatiles from regolith. Generally, they only remove a portion of the oxygen and discard the remainder. Some techniques use a critical consumable that would be unacceptable under the bootstrap ground rules.

A promising all-electric technique is RF Microwave heating of regolith. It was discovered that a simple microwave would melt regolith faster than the same unit would boil water. Early tests indicated that lunar regolith responds to microwaves and that a directed high power microwave beam will yield volatiles and separate metals. ${ }^{12}$ Much more development work is needed but microwave and Radio Frequency induction techniques are most promising.

\section{Non Metallic Products}

Given the wealth of in situ structural materials most major structures will be fabricated from in situ resources. As noted earlier, supporting structures and towers, volatile fluid storage and electric power transmission hardware can be produced on site. Although this discussion has focused on metals there are abundant ceramic materials. Ceramics and glasses will be needed as a substitute for polymers and will be essential as electrical insulators in the power infrastructure. Ceramics are abundant; however, they rarely occur as single metal oxides but as complex minerals.

Ion Sputtering can extract ceramic materials and redeposit them as thin films. This can be useful in making insulated products like capacitors. A number of tests show that regolith can be converted into glass by heating. Glass fiber would be useful for insulating conductors. More investigation is needed to determine how raw lunar glass can be used in the bootstrap operations using simple processes.

For surface repairs or thin material fabrication it may be easier to combine metal and oxygen at the molecular level to create a specific ceramic or glass compound on demand. For example, reactive ion sputtering combines metal ions with oxygen ions to produce high purity metal oxides of silicon, aluminum, titanium, magnesium and zinc. These can be useful as insulators, abrasion resistant coatings, dry lubricants and even piezoelectric elements. 
Table 4: Metal Oxides and Applications

\begin{tabular}{|l|l|}
\hline \multicolumn{1}{|c|}{ Material } & \multicolumn{1}{c|}{ Applications } \\
\hline Aluminum Oxide & Electrical Insulators, Grind \& Polishing Abrasives, Sapphire Optics \\
\hline Magnesium Oxide & High Temperature Refractory Material and Insulator \\
\hline Silicon Oxide & Electrical \& Thermal Insulators, Glass, Quartz, Aerogel \\
\hline Titanium Oxide & Photo-hydrolysis of Water, Photo-Catalytic Cement, Photo Cells \\
\hline Zinc Oxide & Piezoelectric Sensors \& Motors, Semiconductors, Diodes \\
\hline
\end{tabular}

\section{Fabrication from In-Situ Materials}

A common recurring flaw with most resource based scenarios is the tendency to tie in situ resources with mining and the industrial scale of manufacturing. Concepts involving excavators, trucks, and bulldozers are not credible. First they are too large to deliver $(10,000 \mathrm{~kg}=\$ 1$ billion). Second, they will perform very poorly, because many of them rely on gravity to work. Because they need mass and gravity small "light weight" versions, in particular, will not work either. Similarly, industrial machine tools like lathes and mills are massive to resist dynamic forces and light weight versions will perform very poorly. Large scale conventional machinery is ground ruled out of the bootstrap approach. What are needed are process technologies that work with the natural environment and materials. This however, requires examining the fundamental behavior of materials in high vacuum and low gravity.

\section{Small Scale Processing}

To minimize launch mass the bootstrap approach will focus on the technologies that handle and manipulate non volatiles by non mechanical means. In general, these new methods will involve electric methods of manipulating energy and materials. Most non volatiles are fairly evenly distributed in rocks. Regolith (pulverized rock) can be found as powder or dust and easily manipulated by electric or magnetic fields in a high vacuum. Exploiting the fine and easily acquired materials avoids the rock drilling, breaking, and crushing processes that involve massive hardware, produce tremendous wear, and have high power demands. Processing the existing fine powder and dust materials reduces the process equipment to a very manageable scale. Processing materials in small amounts is suitable for a bootstrap process because it minimizes peek power. Bootstrap technologies emphasize flexibility and efficient use of materials but are not concerned with high throughput. High throughput techniques may be brought on line after the bootstrap systems establish a substantial infrastructure.

\section{All-Electric Solutions}

A bootstrap process based on electric technology simplifies the support needs down to the common need for electric power. An "all-electric" philosophy eliminates complex mechanisms and many consumables. Eliminating mechanical complexity further reduces maintenance making processes easier to support. Replacing chemical processes with electric processes eliminates critical chemical consumables and support equipment for storing, dispensing them. All electric processing means fewer failure points and fewer critical resources. By reducing the consumables down to electric power the more power available the more capable the system becomes. With abundant power more in situ materials can be acquired and processed without depending on deliveries from Earth. The investment in electric power generation and all-electric process provides the greatest payoff for the bootstrap approach.

\section{Convergence of Small Scale and All-Electric}

The all-electric approach applies to energy manipulation, as well as, material manipulation. Electron Beam technology is well understood and perfectly suited for the space environment. E-Beam technology has been used for a large variety of processes ranging from precise instruments like scanning electron beam microscopes, to industrial processes like electron beam welding, electron beam vapor deposition, electron beam ablation to Electron Beam Free Form Fabrication. ${ }^{13}$ The electron beam is much more efficient $(\sim 90 \%)$ than equivalent high power LASER processes $(<10 \%)$ it can deliver power precisely and is compatible with high vacuum operation.

The electron beam is unmatched in versatility. It can weld thick plates in a single pass yet weld thin foil. It can precisely heat treat large areas or drill tiny holes. It can vaporize high temperature materials or solder microcircuits. The ability to precisely focus yet sweep, raster or hop between locations gives the electron beam incredible agility and utility. The electron beam is, of course, all-electric. 


\section{Electrostatic/Electromagnetic Manipulation}

To fully exploit the electron beam it must be matched with all-electric materials manipulation methods. Electric material processing must handle small particles. To cover the broadest range of materials requires that matter may be processed in solid, liquid, vapor and plasma state.

- Solid material is manipulated as powders (100 to $<1$ micrometers)

- Liquid material is manipulated as droplets (1000 to $<1$ micrometers $)$

- Vapor material is manipulated at the molecular scale.

- Plasma manipulated at the molecular scale

Electromagnetic and electrostatic fields are often the best way to handle particles in high vacuum. On earth electrostatics are used to precisely handle tiny ink droplets and fine toner particles in desktop printers resulting in fine print and high resolution graphics.

Thus the lunar environment is ideal for manipulated materials by electric means. Solid and liquids particles can be electrically charged and manipulated by electric or magnetic fields. When vapors are ionized they can be manipulated by the same electric or magnetic fields. All-electric methods of manipulating energy and material are a very powerful combination and will lead to versatile and effective process technologies that are fundamentally compatible with the environment.

The conversion of resources from scavenged or lunar resources into usable products is the enabling capability for the bootstrap approach. Many of the techniques will first appear as in situ maintenance operations. Repair techniques are normally derived from the original manufacturing process thus both repair and fabrication is very dependent on the process environment and materials available.

\section{Metallic Products}

Advanced fabrication technologies are described in more detail in the appendix. This section describes some general forms that would be useful in building an infrastructure.

\section{Metals Feedstock Production}

Aluminum and iron are abundant enough and useful in constructing an infrastructure. Normally pure metals are alloyed with other materials to enhance structural properties. Without alloying materials lunar metals should be expected to be comparatively low grade compared to aerospace grade materials. In $1 / 6^{\text {th }}$ gravity the lunar hardware can be substantially overbuilt to compensate for modest material properties. A small amount of alloy materials (vitamin technologies) can be imported from Earth to improve metal properties. ${ }^{14}$

Powder is regarded as the most flexible form of solid feedstock. The simplest approach may be to simply melt metal (potential e-beam application) and create a metal powder feedstock by a combination of ultrasonic and electrostatic means. The acoustic fountain technique, shown below, can be used to create powder. Alternatively, this acoustic technique can also be combined with electrostatics to transfer the droplets directly to another surface to build sheet and plate stock.

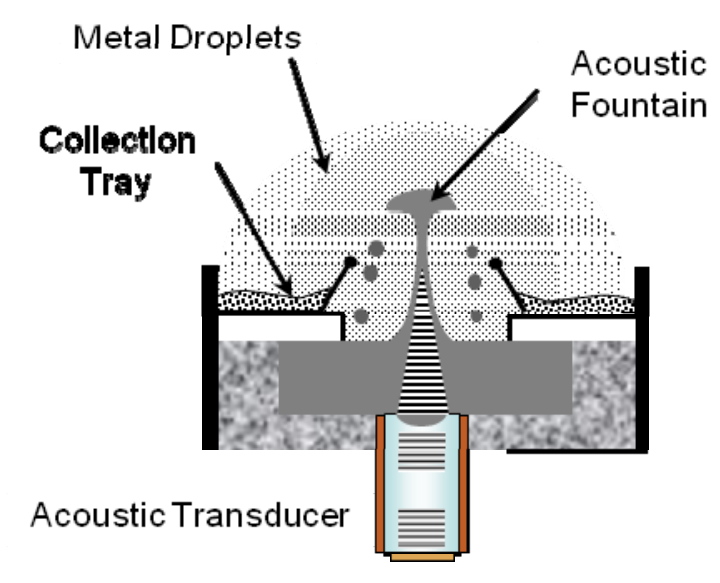

Figure 4: Acoustic Powder production. 


\section{Wire:}

Wire is not only a versatile electrical and structural form but serves as feedstock for many welding and brazing processes. For example, wire is also used in the Electron Beam Free Form Fabrication (EBF3) technology developed by NASA Langley. ${ }^{14}$ As noted earlier, wire production is enabling for conducted power transmission. There are two candidates for aluminum wire production. Conductors may be made by using metal deposited onto composite fiber cores in a manner similar to the soft tool techniques using vapor and droplet deposition techniques. This technique can produce miles of wire from a single fiber spool.

Another technique, particularly for heavy gauge wire, is to use an electron beam melting process to create a raw wire from aluminum powder. This raw form could then be drawn down to a smaller diameter if needed. As shown in the figure below, wire can be formed by simply sintering a narrow path in a powder bed. Unlike the wire process described earlier, this process is pure metal and does not require a fiber core but will likely produce lengths only a few meters long. Converting metal powder into wire provides a convenient form that can be used for both welding for fabrication with very little preparation.

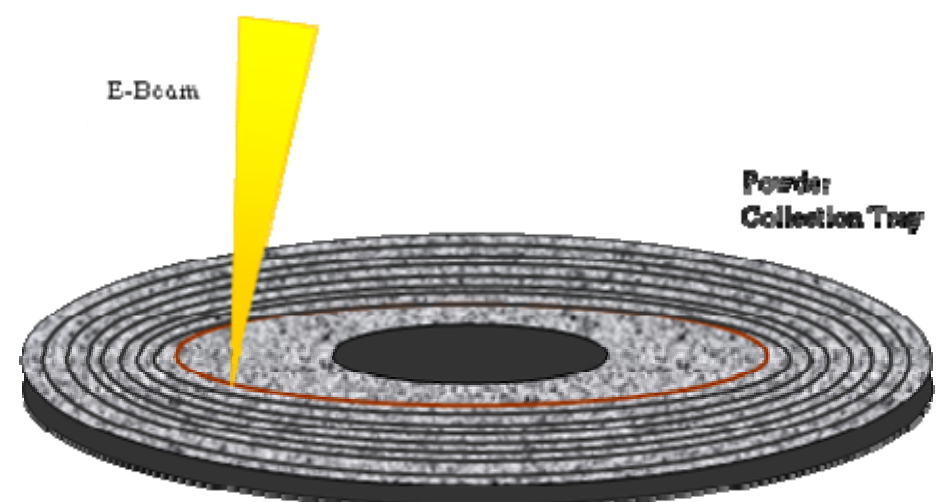

Figure 5: Metal wire formed by electron beam fusing of aluminum powder.

\section{Metal Foils:}

Foils can be formed by a very simple process of melting and vaporizing metal and allowing it to condense upon a thin solid like a polymer film. The user has the option of permanently bonding the metal to the polymer surface or simply peeling the polymer film away. Repeated deposition passes thickens the foil. The Foil can also be thickened by using a fine metal droplet mist formed by the acoustic fountain process also used to make powder. Because of its usefulness for solar energy collection metal foils like metal wire may be one of the few mass produce feedstock products.

\section{Metal Sheet \& Plate:}

Rather than using heavy hot or cold rolling equipment sheet stock can be formed by extending the foil making process. The acoustic fountain method can deposit metal droplets in repeated layers that thickens the foil into a thicker self supporting sheet or plate stock. Alternatively, metal may deposit as a layer of powder and sintered by electron beam techniques. Rather than create an inventory of sheet stock the bootstrap approach will produce sheet on demand. Features like reinforcing ribs or flanges, openings and attachment hard points would be integrated into the sheet at the time of production. By integrating features at the initial production post process drilling and cutting and welding operations are minimized. In many ways this fabrication method is a scaled up version of Free Form Fabrication.

\section{Tubes and Tanks:}

The formation of enclosed tubes and tanks is needed for processing both volatile and non volatile resources. The process would start much like the foil and sheet processes described above but employ inflatable tools described in the "soft tool" section in Appendix A. A polymer inflatable representing a tank would first be coated by vapor or sputter deposition process followed by a slow build up by droplet or powder methods until it became rigid enough to handle. Features like ribs, hatchways and port flanges, support brackets and other features would be added. Similarly piping can be formed using tubular shaped inflatables. Flanged pipes can be joined to the main tank by electron beam welding. Structural tubes for tubular utility towers can support power and communications. Pressure vessels serve as human habitats or volatile processing and containment equipment. Figure 6 illustrates the sequence of using lunar metals to construct and seamless structure. 


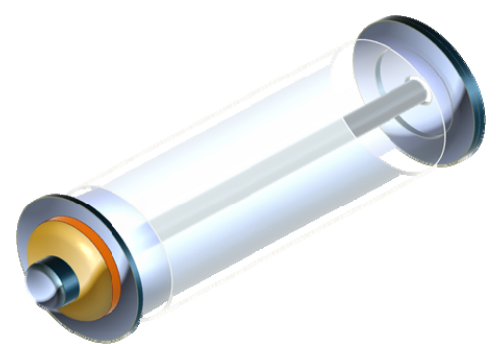

a. An inflated polymer tube is pressurized between two flanges to be used as a "soft tool".

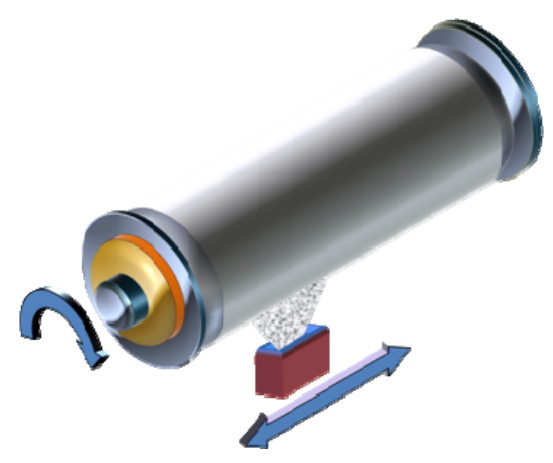

c. Once a thin metal shell has been formed more reinforcing material is deposited by a droplet or powder deposition process. This deposition can merge the end flanges with the shell.

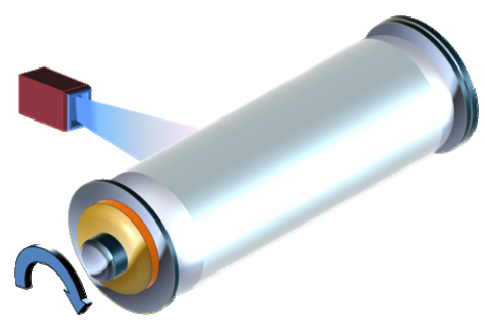

b. Polymer surface is metalized by vapor or ion sputtering deposition to form a thin shell.

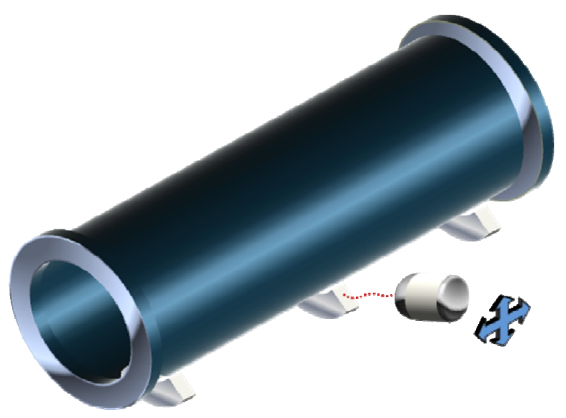

d. Once a thick reinforced shell is complete, The polymer tube is deflated. Details features like flanges brackets and supports are added by free form fabrication techniques or welding. Additional protective coatings can also be applied.

\section{Figure 6: Building a simple cylindrical structure using an inflated soft tool technique.}

\section{Building a Lunar Infrastructure}

\section{A. Building a Power Infrastructure}

Consistent with the bootstrap approach much of the non-volatile and scavenged assets are aimed at expanding the power infrastructure first. As noted, nuclear fission power is an option particularly for the initial capability. Typically solar power is acquired by photovoltaic means which is the easiest to deploy as an imported infrastructure. Production of photo-voltaic cells however is expected to be beyond the in situ capability in the initial phases of the bootstrap approach. However, consistent with the bootstrap approach a there are ways to exploit local resources with fabrication technologies to build and lunar power system from scratch.

\section{Solar Power}

Solar thermodynamic power may be more mechanically complex but may be easier to harness with scavenged and local resources. The availability of even a modest amount of water could support a small steam driven power plant. Solar reflectors, built in-situ using metal and soft tool techniques, described in the appendix, can focus solar energy on a central receiver boiler. By establishing a ring of reflectors around the receiver water can be boiled and drive a small turbo generator constructed from scavenged rocket engine turbines or imported as cargo.

Water would be boiled to drive the steam turbine. Steam would be condensed into water in heat exchangers and recycled using scavenged turbo-pumps. The radiators required for cooling could also be composed of hardware scavenged from a lander propulsion and thermal control systems. Heat can be radiated into space or dissipated in buried water tanks that serve as thermal reservoirs. This system would not be as efficient as a highly engineered solar dynamic system but, it would work and it would require very little upmass other than an electric generator, radiator and system controls. 


\section{Energy Storage}

Energy storage is needed even in the highly illuminated Solar Highlands. When sufficient volatiles are available power can be stored by electrolysis of water into $\mathrm{H}_{2}$ and $\mathrm{O}_{2}$ which can be used in fuel cells. An alternate power storage technique suited for bootstrap is flywheel technology. The main limitation is the mass required for effective storage. However, in-situ iron can be used to create a relatively massive rotating wheel. In this scenario, the core mechanism, electromagnetic elements, and electronics are imported.

\section{Power Lines}

The ability to manufacture conductor wire is enabling for significant power transmission from Solar Highlands to Volatile Lowlands that may be $100 \mathrm{~km}$ or more. Delivery a $100 \mathrm{amp}$ capacity spanning $100 \mathrm{~km}$ would exceed $16,600 \mathrm{~kg}$. It would need 4 to 6 EELV launches. This mass is even beyond the Altair Cargo Lander capacity. The mass is too great to extract from scavenged sources. To save over $\$ 1$ billion of space transportation cost it may be worthwhile to invest in technology that extracts aluminum and produces miles of conductor cable.

As described in a previous section, there are two candidates for aluminum wire production. Conductors may be made by using metal deposited onto composite fiber cores alternatively an electron beam melting process can create a raw wire from aluminum powder. Either technique would supply single strands to be wound into cables. A cable could be constructed from as few as seven heavy strands or many dozens of small strands to make a flexible cable. The need for making cable is critical and worthy of considerable technology investment. The other option is to commit to the development and deployment of a microwave power transmission system.

\section{B. Building a Volatile Resource Infrastructure}

This section describes how volatile resources are extracted once the power infrastructure is connected.

\section{Lunar Water}

Recent missions confirmed the presence of water at the lunar poles and it appears to be in relatively high concentration as a water regolith mix. Water extraction processes may be easy to perform simply by injecting heat into the surface and collecting the vapors emitted. Operations may look more like tent shrouded drilling rigs rather than the sprawling strip mines that other oxygen harvesting schemes have described. The main problem is physical access to the crater sites and the extreme cold expected.

\section{Electrical and Transportation Access}

The Solar Highland power system that has been expanding under the bootstrap approach provides the needed power. Mobile robotic units will have assembled a power transmission infrastructure to deliver power to the Volatile Lowland sites. The need for reliable mobility into and out of deep craters may be met with a suspended cableway to transport equipment into the site and products out of the site.

Erecting said cableway is the initial challenge. A cable may be strung by lowering a robot from the upper rim tethered by a Kevlar rope. ${ }^{15}$ If the slope is not passable or too steep, an alternative may be to equip a robot with propulsive thrusters to fly into crater while deploying a light feeder line that helps pull the cable into position. Both conductive and mechanical cables can be deployed once an anchor point is established on the crater floor. Once set up the mechanical cable will be used to transport equipment in and lift ice out. 


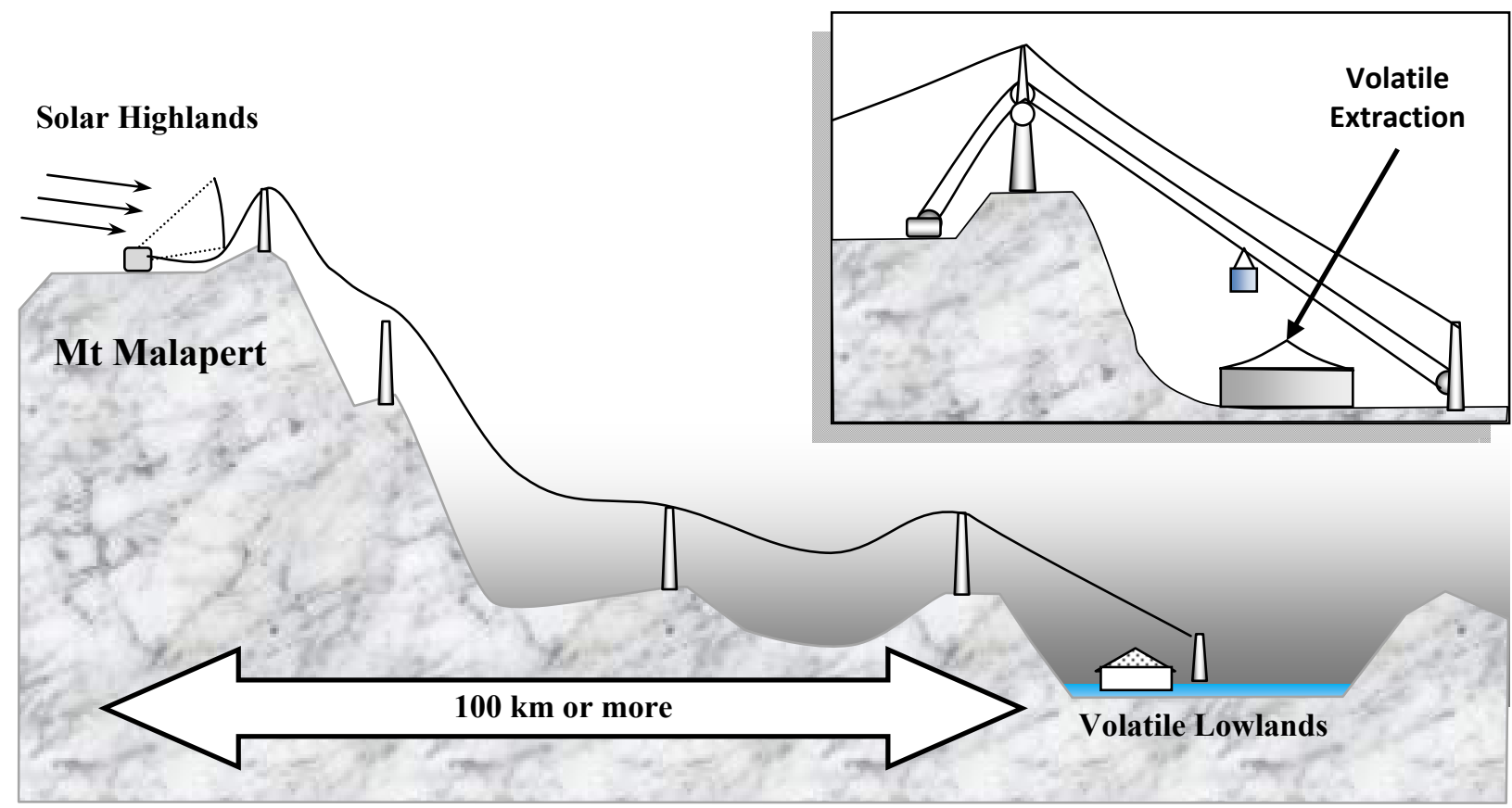

Figure 7: Electrical Power and Transport Cable System.

\section{Water Vapor Extraction}

As long as the water density is a few percent or more, water can be extracted with a simple heat vaporization, condensation and freezing cycle. Heating may be done by a number of methods including radiant heat, conductive penetrating probes, injection of electric current, and microwave beams.

Consistent with the bootstrap approach water vapor extraction will exploit the environment. A tent-like impermeable shroud covers an extraction site. Inside, a labyrinth of condenser panels hang above the ground and are allowed to chill to ambient conditions. Localized heating is applied to the ground causing water vapors to arise into the vacuum and condense on the chilled panels. Periodically the heating halts and the ice covered panels are removed and lifted from the crater to a processing site. The cableway may transports these panels to a processing site outside the crater. The ice panels are placed in a containment tank where they are heated and the water is collected and stored. The panels are then returned to the water extraction site.

\section{Water and Volatile Processing}

The collected water is eventually hydrolyzed into $\mathrm{O}_{2}$ and $\mathrm{H}_{2}$ propellants. ${ }^{16}$ For cryogenic storage, significant compressor and cryo-cooling will be needed. Considerable power may be saved if the liquefying process is assisted by the naturally extreme cold that exists in certain craters. Further, the same extreme cold can be used to preserve $\mathrm{O}_{2}$ and $\mathrm{H}_{2}$ with minimum of power. Early volatile storage needs are met by reusing lander propellant tanks. However, as the process scales up tanks can be constructed by soft tool metallization techniques describe in the fabrication section.

Once water is acquired it can be exploited for bootstrap purposes. Until water is available all processing is "dry" so to avoid consumables. With water becoming abundant wet processing can be used where water serves as a transport media. Water may also be used as steam, as described in power infrastructure section, for solar powered steam turbine power generation. Steam power may be used for mechanical power as a substitute for pneumatic and hydraulic systems found on heavy equipment. 


\section{Beyond Bootstrap}

\section{A. Expanding Human Options}

Given enough time volatile resources will be produced in large enough quantities to eliminate the need to transport water and propellants from Earth. The program now has the option of continuing on with or without human crews. The bootstrap approach can dramatically reduce the costs of sending humans to the moon but is not strictly dependent on human return to the moon for justification. The bootstrap infrastructure is a permanent infrastructure and offers the option for a less costly exploration program. It makes deep space exploration available to anyone or any country that can put a human in orbit.

The direct and tangible economic benefit to this approach is the production and export of valuable propellants that reduces the per kilogram cost of launches by reducing the need to carry propellants beyond low earth orbit. Robotic and human spacecraft can now reduce their propellant upmass and dedicate more payload capacity to scientific equipment, satellite capability or consumables for the crew. This in turn means longer and more productive missions for human crews. For robotic missions this means more instruments and more science equipment. For commercial missions it means more communications bandwidth and broader services or using smaller less costly launch vehicles.

Unlike launching propellants from Earth a modest launch capability on the Moon can efficiently place tons of propellant within easy reach of spacecraft. Placing a vehicle in lunar orbit from the moon surface is 30 times more efficient than from the Earth.

\section{B. Reusable Spacecraft}

The program now has an option of refueling on the surface, in lunar orbit, at Lagrange points and even low Earth orbit. Even after the long journey to Earth, bringing propellants to low Earth orbit still requires far less energy than launching from Earth. The availability of consumables now becomes more cost effective to accommodate human crews either for a much wider lunar exploration or for missions to Mars and Asteroids. With the capacity to refuel and refurbish propellants it is no longer necessary to discard spacecraft after every mission. A durable reusable spacecraft like an Orbital Transfer Vehicle (OTV) in combination with a "Reusable Lander" becomes a viable option. ${ }^{17}$ Many studies have suggested OTV and orbiting refueling stations but until now they did not benefit from the value of lunar water. This resource can be used to build permanent space architecture and eliminate the costly practice of discarding billion dollar spacecraft.

\section{Options for Space Commerce}

The value of the propellants is so high that a form of trade may take place. Earth launched spacecraft can carry small secondary payloads of imported materials or equipment to trade for propellants. International partners, multinational consortiums and even commercial launch firms can trade their secondary payloads for in situ propellants. By doing this the lunar infrastructure no longer needs its own dedicated launch services. In effect, this establishes the first extra-terrestrial commerce based on the exchange of lunar consumables for Earth hardware. The exchange can happen at lunar orbit but the best benefit for users occurs at low Earth Orbit. Users simply need to make it to low Earth orbit and after the exchange; the user's spacecraft can then depart, fully fueled, for GeoSynchronous Orbit, the Moon, Mars or Near Earth Objects. This means small launch vehicles can now reach beyond earth orbit. 


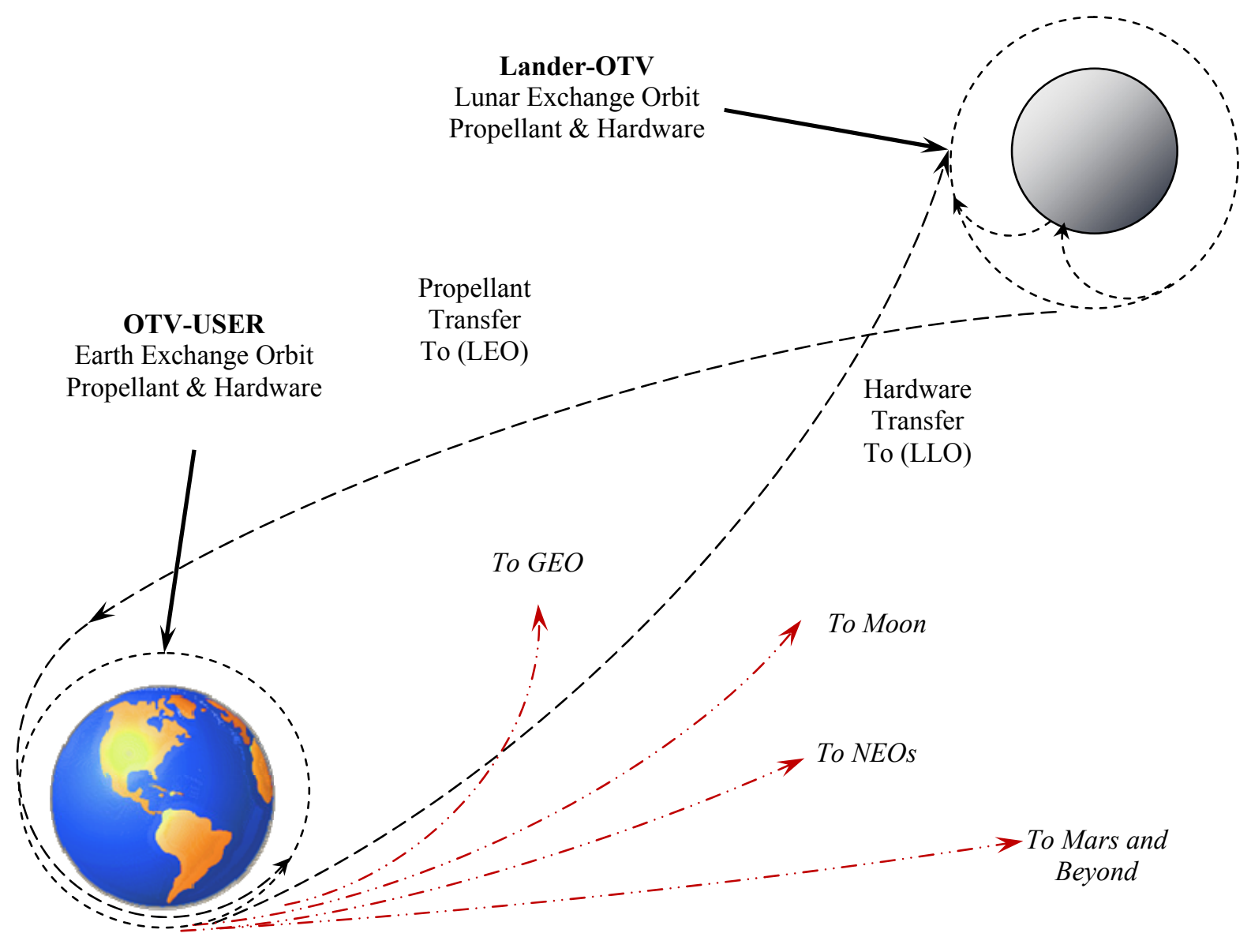

Figure 8: Cis-Lunar Propellant Commerce.

\section{Conclusion}

This paper examined the potential to build an affordable sustainable exploration program without the huge upfront costs. The bootstrap approach reduces the upfront cost by establishing a lunar resource based infrastructure that precedes and then supports the greater human exploration effort. The intent of the bootstrap approach is to make human spaceflight less risky, less expensive and provide wider options for exploration by tapping into the resources already found in space. It helps create a supportable program by enabling the use of reusable spacecraft or preserves the hardware through scavenging. It also eliminates the incredibly wasteful practice of destroying spacecraft after every human mission.

In most concepts, lunar in situ resources utilization trails behind humans returning to the moon. This delay diminishes the impact and provides little benefit for lunar exploration. In contrast, the Bootstrap Approach fully embraces the benefit of lunar resources by pulling it into the near term robotic phase of exploration that precedes human flights to the moon. The Bootstrap Approach also elevates the importance of acquiring and exploiting lunar solar power and non-volatile materials like metals.

The Bootstrap Approach requires investing in technologies now and deploying them well before humans return to the moon. To minimize cost, the bootstrap approach builds a space infrastructure from very modest initial capabilities. The bootstrap approach relies on low resource demands of tele-robotics not only as a precursor to human operations but as a means to build the infrastructure to accommodate humans.

By definition, the bootstrap approach places emphasis on surviving with low resources and exploiting available resource to grow the capacity to gather more resources. The approach places a focus on power as the primary resource; it employs non volatile resources and fabrication technology to literally build capacity. It defers volatile resource processing until the infrastructure is adequately positioned to exploit it. To minimize dependencies, the bootstrap approach favors all-electric process technologies that eliminate consumables and provides durability, flexibility and simplicity. 
The Bootstrap Approach also considers the prospect of space resource based commerce. Most prior scenarios consider commercialization only after human outposts are established. In this approach, commerce begins in the robotic phase when resource sites produce exportable propellants. In the end, the Bootstrap Approach creates a resource environment that is friendlier to human operations and ultimately makes it easier to extend human presence beyond Earth orbit.

\section{References}

${ }^{1 .}$ Larson W.J., Pranke L.K., "Human Space Flight Mission Analysis and Design,” McGraw-Hill, New York, NY, Oct. 1999.

2.Zapata, E., Levack, D.J., Rhodes, R.E., Robinson, J.W., "Shuttle Shortfalls and Lessons Learned for the Sustainment of Human Space Exploration," AIAA-2009-5346, AIAA/ASME/SAE/ASEE Joint Propulsion Conference, Denver, Co., 2009.

${ }^{3}$ Spudis P.D., "The Moon: Port of Entry to Cislunar Space," http://www.spudislunarresources.com/Papers/ 12SpudisNDU.pdf, April 2010.

4. Joosten B.K, Guerra L.A., "EARLY LUNAR RESOURCE UTILIZATION: A KEY TO HUMAN EXPLORATION," by Kent Joosten \& Lisa Guerra (AIAA 93-4784).

5. Robinsin, M.S., Jolliff, B., Lawrence, S., "LRO Results and implications for Lunar Science Priorities," Presentation to IPP Decadal Survey, October 2009.

6. "National Security Space Launch Report," Rand National Defense Research Institute, 2006.

${ }^{7}$ NASA Constellation Program Lunar Lander: LDAC-2 Spacecraft Performance Analysis Report (SPAR), July 2008.

${ }^{8}$ Mason L.S., Poston D.I., "A Summary of NASA Architecture Studies Utilizing Fission Surface Power," Technology, AIAA 2010-(to be published).

${ }^{9}$ Duerk D.P., "Architecture Student Designs to Support Microhab Sortie Mission," AIAA-2009-6421, AIAA Space 2009 Conference Pasadena, CA. 2009.

${ }^{10 .}$ McNutt C.J., Vick, R., Whiting, H., Lyke, J., Modular Nano-Satellites - (Plug and Play) PnP CubeSat, AIAA, 7th Responsive Apace Conference. April 2009.

${ }^{11}$ Heiken, G.H., Vaniman, D.T., and French, B.M. (1991) Lunar Sourcebook - A User's Guide to the Moon. Cambridge University Press, New York.

12. Taylor L.A., Meek T.T., "Microwave Sintering of Lunar Soil: Properties, Theory, and Practice." p. 196, J. Aerospace Engineering, ASCE, July 2005.

13. Taminger, K.M.B., and Hafley, R.A., "Characterization of 2219 Aluminum Produced by Electron Beam Freeform Fabrication," Proceedings of 13th SFF Symposium, Austin, TX, pp. 482-489 (2002).

14. Freitas Jr., R., Advanced Automation for Space Missions, Proceedings of the 1980 NASA/ASEE Summer Study, 1980.

${ }^{15 .}$ Bash, J.F., HANDBOOK OF OCEANOGRAPHIC WINCH, WIRE AND CABLE TECHNOLOGY, Third Edition, National Science Foundation.

16. Sanders G.B., et al., "Regolith \& Environment Science, and Oxygen \& Lunar Volatile Extraction (RESOLVE) for Robotic Lunar Polar Lander Mission,” International Lunar Conference, 2005.

17. NASA-CR-183551, "Orbital Transfer Vehicle Concept Definition and Analysis Study, Midterm Review," Martin-Marietta Corp., July 1987. 



\section{Appendix A: In-Situ Fabrication Technologies}

\section{A. Advanced Free Form Fabrication}

Recently, a new generation of techniques that can construct truly functional metal parts from digital data has evolved. Collectively called "Free Form Fabrication" (FFF), these technologies employ high power laser or electron beam techniques that are very suited to the high vacuum environment. The material properties of the FFF products have advanced to a point that companies are working toward qualifying the processes for aerospace applications. The benefit of FFF technologies for lunar bootstrap is that most any component can be constructed in-situ without massive tools, dies or machine tools. Thus any metal, regardless of the source, can be shaped into the desired end product. In space, these processes can be dramatically scaled up because the vacuum chamber is eliminated.

The only barrier that prevents these processes from revolutionizing the metal fabrication industry is the need to perform post process finishing operations. Fortunately, the same technologies that can perform surface repair, described earlier, can also perform finishing operations. That is, surface repair technologies and technologies for finishing FFF products are the same technologies.

\section{B. Progressive Refinement}

Progressive Refinement Fabrication combines Additive and Subtractive processes that work together in a closed loop system that corrects deposition errors along the way. Further the process progressively reduces the scale of additive processes as it approaches a predefined product envelope. By progressing from micro-scale particles to molecular scale particles the process slowly converges on the final finished product. The intent is to dramatically improve surface accuracy and finish while eliminating post process machining. Ion implantation and sputtering may alter surface properties and apply protective coatings.

Initial Millimeter-Micrometer Scale:

+ Additive: Weld Wire or Powder Deposition

- Subtractive: Electron Beam Ablation and Glazing

Intermediate Micrometer-Nanometer Scale:

+ Additive: Droplet or Colloidal Deposition

- Subtractive: Electron Beam Ablation or Ion Etching

Finishing Molecular Scale:

+ Additive: Vapor or Ion (sputtering) Deposition

- Subtractive: Ion Etching or Focused Ion Beam Milling

\section{Pre-Encapsulation}

This technique uses FFF deposition to build up the rough structural shape around precise prefabricated, pre encapsulated finished components. These imported components provide the finished surfaces that would otherwise need to be created by post process machining. To protect the component from contamination or heat damage the device is pre-encapsulated with a protective layer of the bulk material. For example a steel threaded piece encapsulated with aluminum. This approach is similar to inserts installed in cast products or weld-on features designed to be welded in place on a larger structure. 


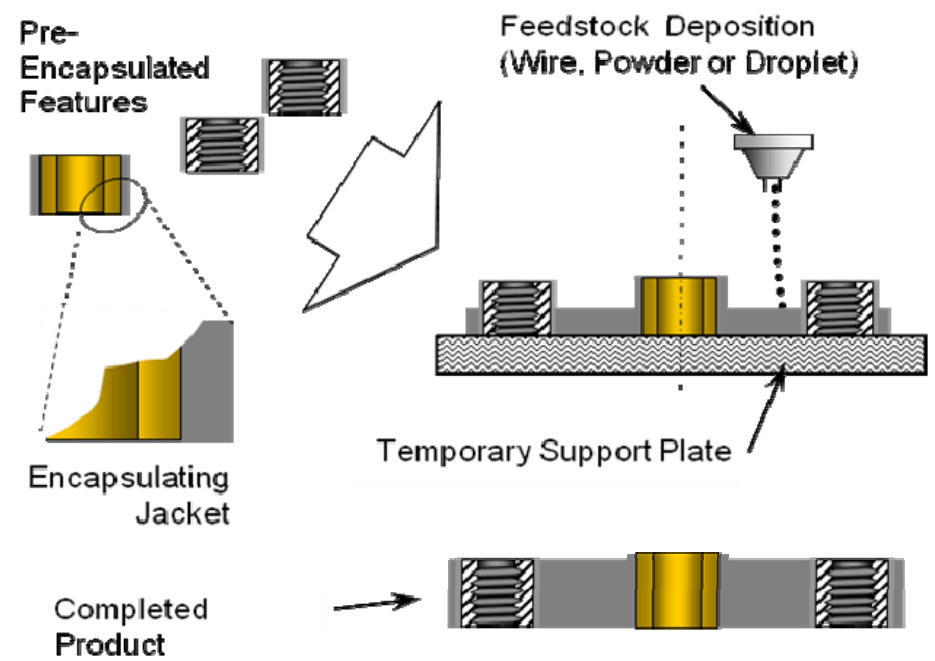

Figure A1: Pre-encapsulation.

\section{Soft Tool Techniques for Precise Surfaces}

Another technique takes advantage of the ability to deposit a small amount of material and its small amount latent thermal energy onto a relatively low temperature soft surface. Researchers have demonstrated a technique of forming optical reflectors by depositing aluminum vapor onto an inflated polymer sphere. This process can be extended by taking the shell formed by vapor deposition and then reinforcing it by a droplet or powder accretion process. This technique may be applied to produce mechanical bearing surfaces. The soft tool approach may be extended to large scale containment vessels and habitats
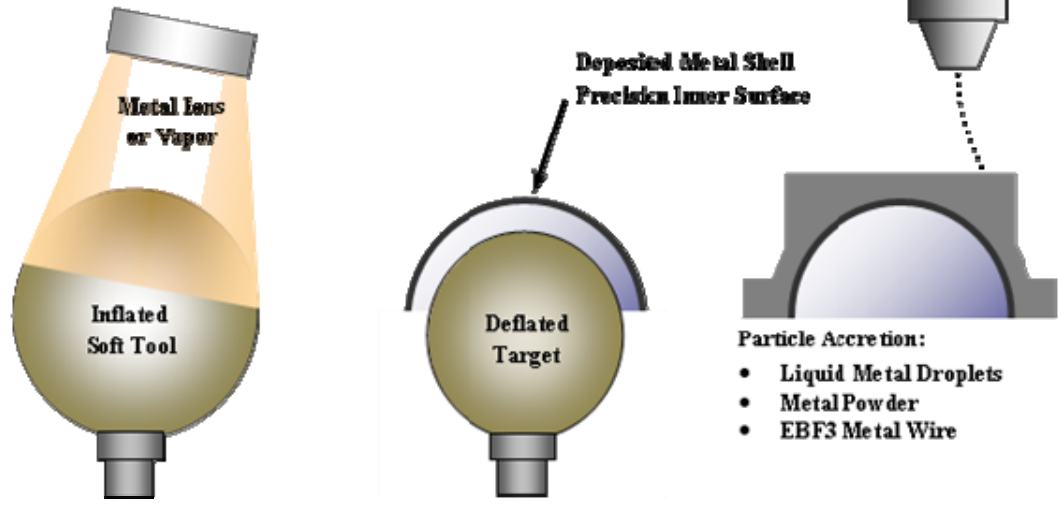

Figure A2: Soft Tool Component Fabrication.

\section{E. In-Situ Fabricated Assemblies}

Assemblies may be composed of a mix of hardware and materials from various sources including scavenged hardware, Pre-Encapsulated hardware, and FFF fabricated components. Electron beam welding is uses to integrate the parts and Ion Sputtering is used to apply a layer of dry lubrication. 


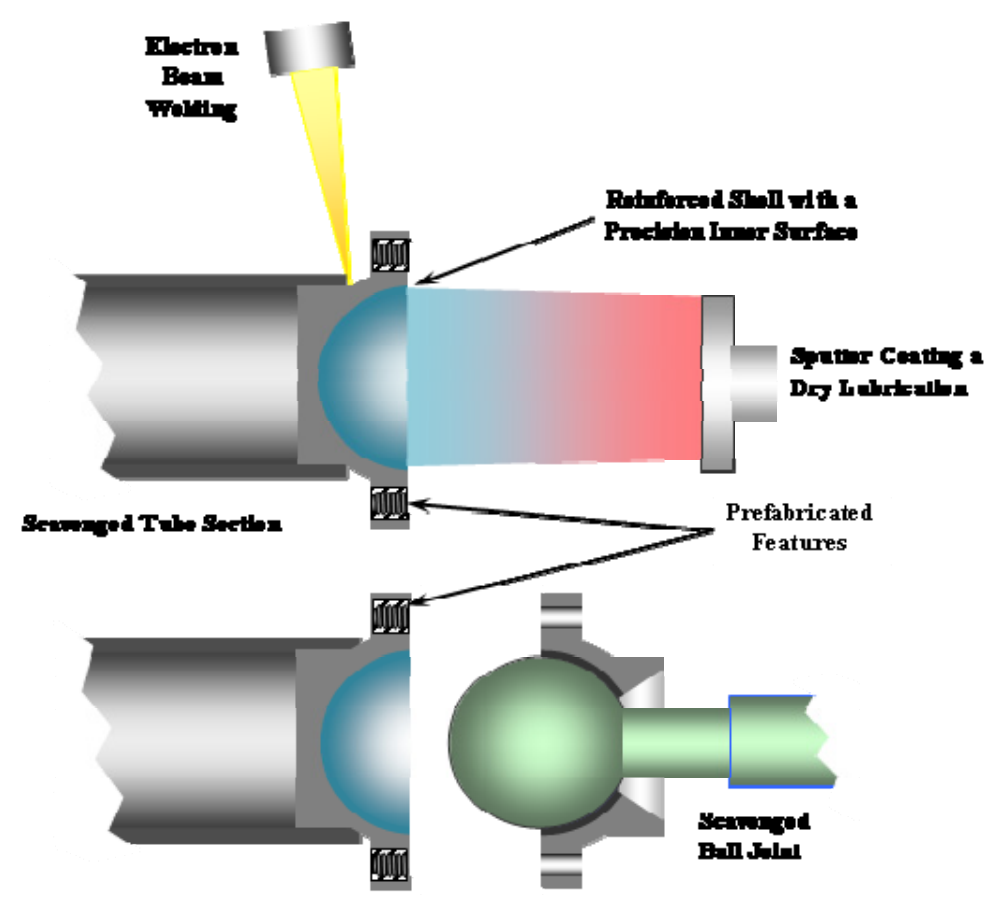

Figure A3: Assembly composed of fabricated and scavenged parts.

\section{F. Soft Tool Approach to Large Structures}

The Soft Tool approach can be applied to larger inflatable structures. Large inflatable polymer films or fabric balloons imported from Earth, are metalized by a combination of metal vapor deposition, metal droplet or powder metal accretion into self supporting structures. Metal tubular structures or pressurized tanks and pipes may be built by "metal over inflatable" techniques. For large structures the precision of the inner surface is less important than the pressure integrity.

The shell is then reinforced by additional layers of solidified metal. The final structure may include adding ribs, brackets, flanges or other features that are accreted directly to the surface or welded on components. Further, special components may be added by the Pre-encapsulation methods described earlier. With careful process control it will be possible to integrate complex mechanisms like pre-encapsulated valve assemblies.

This process is very analogous to how large composite structures are built. Once complete, the inflated polymer may remain as an impermeable membrane or it may be removed as a reusable soft tool. Removal also facilitates adding internal features and if needed outfitting the interior. This method and can be employed in construction of very large seamless pressurized structures much larger and more massive than can be practically launched from Earth.

Non-inflated structures can be fabricated in-situ with the aid of a temporary working surface. Flat sheets of material of metal foil or polymer films may be used as the high quality finish side of a structure. Large solar reflector mirrors, for example. It's been suggested that even heat shrink films could be used for the initial shape. Clearly this approach will not replace the complex electronics, mechanisms and instruments. But these small devices and easily imported "vitamin technology" that can be integrated into structures. As noted earlier, many small components can be scavenged from flight hardware. The main benefit of Free Form Fabrication and Soft Tool techniques is that they make it possible to exploit in situ and scavenged metals with an absolute minimum of manufacturing machinery 


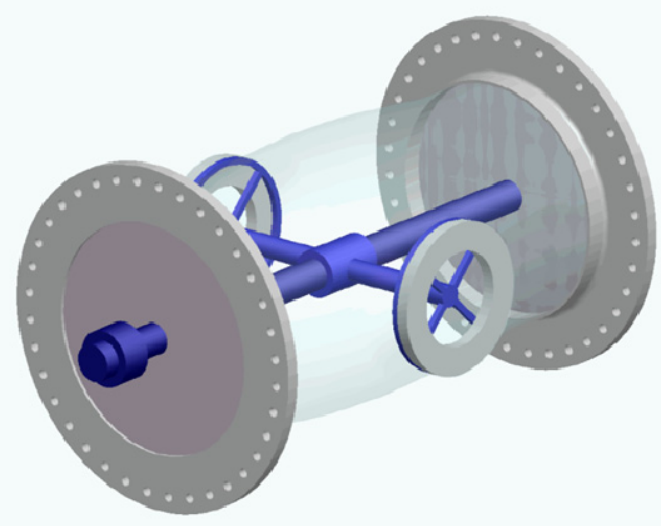

$$
\text { Inflated polymer "soft tool" with }
$$
prepositioned metal flanges

Complete pressure vessel built from metal deposited over the soft tool by specialized robots

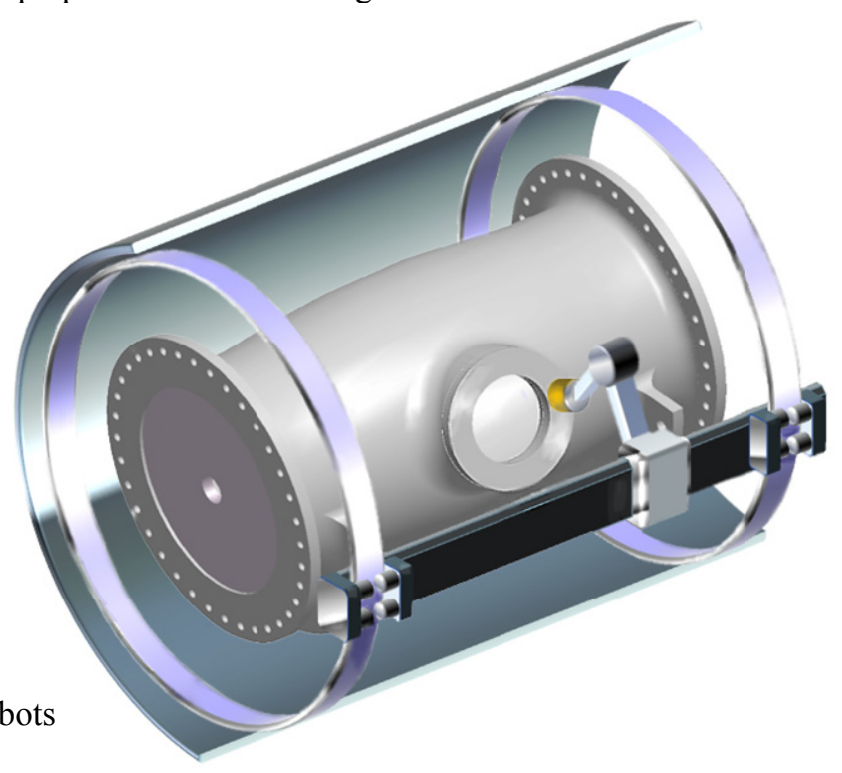

Figure A4: Building large structures with an inflated soft tool technique. 


\begin{tabular}{|c|c|c|c|c|c|}
\hline \multicolumn{5}{|c|}{ REPORT DOCUMENTATION PAGE } & $\begin{array}{l}\text { Form Approved } \\
\text { OMB No. 0704-0188 }\end{array}$ \\
\hline \multicolumn{6}{|c|}{ 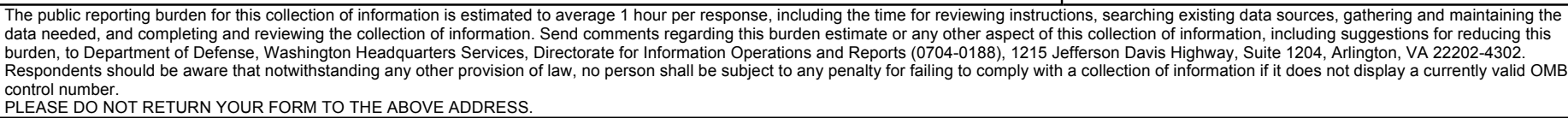 } \\
\hline \multicolumn{2}{|c|}{$\begin{array}{l}\text { 1. REPORT DATE (DD-MM-YYYY) } \\
01-01-2011\end{array}$} & \multicolumn{3}{|c|}{$\begin{array}{l}\text { 2. REPORT TYPE } \\
\text { Technical Memorandum }\end{array}$} & 3. DATES COVERED (From - To) \\
\hline \multirow{3}{*}{\multicolumn{5}{|c|}{$\begin{array}{l}\text { 4. TITLE AND SUBTITLE } \\
\text { A Bootstrap Approach to an Affordable Exploration Program }\end{array}$}} & 5a. CONTRACT NUMBER \\
\hline & & & & & 5b. GRANT NUMBER \\
\hline & & & & & 5c. PROGRAM ELEMENT NUMBER \\
\hline \multirow{3}{*}{\multicolumn{4}{|c|}{$\begin{array}{l}\text { 6. AUTHOR(S) } \\
\text { Oeftering, Richard, C. }\end{array}$}} & & 5d. PROJECT NUMBER \\
\hline & & & & & 5e. TASK NUMBER \\
\hline & & & & & $\begin{array}{l}\text { 5f. WORK UNIT NUMBER } \\
\text { WBS } 825855.01 .03 .03 .03\end{array}$ \\
\hline \multicolumn{5}{|c|}{$\begin{array}{l}\text { 7. PERFORMING ORGANIZATION NAME(S) AND ADDRESS(ES) } \\
\text { National Aeronautics and Space Administration } \\
\text { John H. Glenn Research Center at Lewis Field } \\
\text { Cleveland, Ohio 44135-3191 }\end{array}$} & $\begin{array}{l}\text { 8. PERFORMING ORGANIZATION } \\
\text { REPORT NUMBER } \\
\text { E-17468 }\end{array}$ \\
\hline \multirow{2}{*}{\multicolumn{5}{|c|}{$\begin{array}{l}\text { 9. SPONSORING/MONITORING AGENCY NAME(S) AND ADDRESS(ES) } \\
\text { National Aeronautics and Space Administration } \\
\text { Washington, DC 20546-0001 }\end{array}$}} & $\begin{array}{l}\text { 10. SPONSORING/MONITOR'S } \\
\text { ACRONYM(S) } \\
\text { NASA }\end{array}$ \\
\hline & & & & & $\begin{array}{l}\text { 11. SPONSORING/MONITORING } \\
\text { REPORT NUMBER } \\
\text { NASA/TM-2011-216889 }\end{array}$ \\
\hline \multicolumn{6}{|c|}{$\begin{array}{l}\text { 12. DISTRIBUTION/AVAILABILITY STATEMENT } \\
\text { Unclassified-Unlimited } \\
\text { Subject Category: } 20 \\
\text { Available electronically at http://www.sti.nasa.gov } \\
\text { This publication is available from the NASA Center for AeroSpace Information, 443-757-5802 }\end{array}$} \\
\hline \multicolumn{6}{|c|}{ 13. SUPPLEMENTARY NOTES } \\
\hline \multicolumn{6}{|c|}{$\begin{array}{l}\text { 14. ABSTRACT } \\
\text { This paper examines the potential to build an affordable sustainable exploration program by adopting an approach that requires investing in technologies that can be used to } \\
\text { build a space infrastructure from very modest initial capabilities. Human exploration has had a history of flight programs that have high development and operational costs. } \\
\text { Since Apollo, human exploration has had very constrained budgets and they are expected be constrained in the future. Due to their high operations costs it becomes necessary } \\
\text { to consider retiring established space facilities in order to move on to the next exploration challenge. This practice may save cost in the near term but it does so by sacrificing } \\
\text { part of the program's future architecture. Human exploration also has a history of sacrificing fully functional flight hardware to achieve mission objectives. An affordable } \\
\text { exploration program cannot be built when it involves billions of dollars of discarded space flight hardware, instead, the program must emphasize preserving its high value space } \\
\text { assets and building a suitable permanent infrastructure. Further this infrastructure must reduce operational and logistics cost. The paper examines the importance of achieving a } \\
\text { high level of logistics independence by minimizing resource consumption, minimizing the dependency on external logistics, and maximizing the utility of resources available. } \\
\text { The approach involves the development and deployment of a core suite of technologies that have minimum initial needs yet are able expand upon initial capability in an } \\
\text { incremental "bootstrap" fashion. The "bootstrap approach" incrementally creates an infrastructure that grows and becomes self sustaining and eventually begins producing the } \\
\text { energy, products and consumable propellants that support human exploration. The bootstrap technologies involve new methods of delivering and manipulating energy and } \\
\text { materials. These technologies will exploit the space environment, minimize dependencies, and minimize the need for imported resources. They will provide the widest range of } \\
\text { utility in a resource scarce environment and pave the way to an affordable exploration program. }\end{array}$} \\
\hline \multicolumn{6}{|c|}{$\begin{array}{l}\text { 15. SUBJECT TERMS } \\
\text { Logistics; Flight operations; Space architecture; Supportability; Lunar; In situ resource }\end{array}$} \\
\hline \multicolumn{3}{|c|}{ 16. SECURITY CLASSIFICATION OF: } & $\begin{array}{l}\text { 17. LIMITATION OF } \\
\text { ABSTRACT }\end{array}$ & $\begin{array}{l}\text { 18. NUMBER } \\
\text { OF }\end{array}$ & $\begin{array}{l}\text { 19a. NAME OF RESPONSIBLE PERSON } \\
\text { STI Help Desk (email:help@sti.nasa.gov) }\end{array}$ \\
\hline $\begin{array}{l}\text { a. REPORT } \\
\text { U }\end{array}$ & $\begin{array}{l}\text { b. ABSTRACT } \\
\text { U }\end{array}$ & $\begin{array}{l}\text { c. THIS } \\
\text { PAGE } \\
\text { U }\end{array}$ & UU & $\begin{array}{l}\text { PAGES } \\
29\end{array}$ & $\begin{array}{l}\text { 19b. TELEPHONE NUMBER (include area code) } \\
443-757-5802\end{array}$ \\
\hline
\end{tabular}



